\title{
Location of a-tocopherol and a-tocotrienol to heterogeneous cell membranes and inhibition of production of peroxidized cholesterol in mouse fibroblasts
}

Toshiyuki Nakamura ${ }^{1,2}$, Ayako Noma $^{1}$ and Junji Terao ${ }^{1 *}$

\begin{abstract}
Background: $\mathrm{a}-\mathrm{Tocopherol}(\mathrm{a}-\mathrm{T})$ and a-tocotrienol ( $\mathrm{a}-\mathrm{T} 3)$ are well recognized as lipophilic antioxidants. Nevertheless, there is limited knowledge on their location in heterogeneous cell membranes. We first investigated the distribution of $\mathrm{a}-\mathrm{T}$ and $\mathrm{a}-\mathrm{T} 3$ to the cholesterol-rich microdomains (lipid rafts and caveolae) of heterogeneous cell membranes by incubating these antioxidants with cultured mouse fibroblasts.

Findings: Levels of cellular uptake for a-T and a-T3 were adjusted to the same order, as that of the latter was much more efficient than that of the former in the cultured cells. After ultracentrifugation, $a-T$ and $a-T 3$ were partitioned to the microdomain fractions. When the distribution of $\mathrm{a}-\mathrm{T}$ and $\mathrm{a}-\mathrm{T} 3$ was further confirmed by using methyl- $\beta$ cyclodextrin (which removes cholesterol from membranes), a-T was suggested to be distributed to the microdomains (approx. 9\% of the total uptake). The same treatment did not affect a-T3 content in the microdomain fractions, indicating that $\mathrm{a}-\mathrm{T} 3$ is not located in these cholesterol-rich domains. However, a-T and a-T3 significantly inhibited the production of peroxidized cholesterol when cells were exposed to ultraviolet-A light.
\end{abstract}

Conclusions: These results suggest that $\mathrm{a}-\mathrm{T}$ and $\mathrm{a}-\mathrm{T} 3 \mathrm{can}$ act as membranous antioxidants against photo-irradiated cholesterol peroxidation irrespective of their distribution to cholesterol-rich microdomains.

Keywords: a-Tocopherol; a-Tocotrienol; Cholesterol hydroperoxide; Microdomains; Lipid rafts; Ultraviolet (UV)-A irradiation

\section{Introduction}

$\alpha$-Tocopherol $(\alpha-\mathrm{T})$ and $\alpha$-tocotrienol $(\alpha-\mathrm{T} 3)$ are vitamin E homologs. They possess a chromanol group (which is responsible for free radical-scavenging activity) and hydrocarbon side chains (which allows them to localize in hydrophobic biomembranes) (Niki et al. 1989). Among vitamin $\mathrm{E}$ homologues, $\alpha-\mathrm{T}$ is known to circulate exclusively in the human body (Hosomi et al. 1997). It is suggested that $\alpha$-T3 barely circulates in the body because of the specificity of $\alpha-T$ transfer to liver proteins and its rapid and preferential metabolism (Yamashita et al. 2002; Ikeda et al. 2003). However, it has been reported that $\alpha$-T3

\footnotetext{
* Correspondence: terao@nutr.med.tokushima-u.ac.jp

1 Department of Food Science, Institute of Health Bioscience, Tokushima University Graduate School, 3-18-15 Kuramoto-cho, Tokushima 770-8503, Japan Full list of author information is available at the end of the article
}

accumulates selectively in the skin tissue of rodents (Ikeda et al. 2000). In addition, $\alpha-\mathrm{T} 3$ was reported to possess higher antioxidant activity than $\alpha-T$ in lipid peroxidation in rat liver microsomal membranes and oxidative damage of cytochrome P-450 (Serbinova et al. 1991; Suzuki et al. 1993). Therefore, $\alpha$-T3 seems to also act as an in vivo antioxidant in biomembranes, as observed for $\alpha-\mathrm{T}$.

Cholesterol is one of the essential lipids constituting cell membranes. Previously, we proposed that cholesterol hydroperoxides (ChOOHs) formed by exposure of skin tissue to ultraviolet (UV)-A irradiation induce skinphotoaging via activation of collagen-hydrolyzing matrix metalloproteinases (MMPs) (Minami et al. 2009). In addition, ChOOHs were found to be produced in the cholesterol-rich domains of cell membranes, namely, microdomains (lipid rafts and caveolae) (Nakamura et al. 
2013). Microdomains are recognized as the site of cell membranes where a wide variety of signal transduction pathways start to propagate in the cytoplasm (Simons and Ikonen 1997). Therefore, it is likely that physicochemical changes in the microdomains originating from $\mathrm{ChOOHs}$ formation result in the modification of signal transduction leading to MMPs activation.

The aim of the present study was to ascertain the distribution of $\alpha-\mathrm{T}$ and $\alpha-\mathrm{T} 3$ in the cholesterol-rich microdomains of heterogeneous cell membranes as well as their effectiveness in the inhibition of production of $\mathrm{ChOOHs}$ induced by irradiation with UV-A light. Mouse fibroblasts were used as a model of dermal cells and irradiated with UV-A light after treated with $\alpha-\mathrm{T}$ or $\alpha-\mathrm{T} 3$.

\section{Materials and methods}

NIH-3T3 mouse fibroblasts were cultured as described previously (Nakamura et al. 2013). $\alpha-\mathrm{T}$ or $\alpha-\mathrm{T} 3$, which was dissolved in Dulbecco's modified Eagle's medium (DMEM) (final concentrations at $0.05-5 \mu \mathrm{M}$ containing $0.1 \%$ dimethyl sulfoxide), was added to cultured cells and incubated for $24 \mathrm{~h}$. To confirm vitamin $\mathrm{E}$ distribution into microdomains after treatment of $\alpha-\mathrm{T}(5 \mu \mathrm{M})$ or $\alpha$-T3 $(0.5 \mu \mathrm{M})$, cholesterol was removed by replacement with $10 \mathrm{mM}$ methyl- $\beta$-cyclodextrin $(\mathrm{M} \beta C D)$ in serum-free medium (Zidovetzki and Levitan 2007), and cultured cell was further incubated for $30 \mathrm{~min}$. Cells were washed once with $0.5 \%$ bovine serum albumin in phosphate-buffered saline (PBS), and then washed twice in PBS. Cell lysates were collected in $1 \mathrm{~mL}$ of lysis buffer containing 1\% Triton X-100.

For the partition of microdomains in cell membranes, cell lysates were subjected to ultracentrifugation and fractionated as described previously (Nakamura et al. 2013). Each fraction was extracted with hexane for analyses of $\alpha-\mathrm{T}$ and $\alpha-\mathrm{T} 3$ as described previously (Bando et al. 2003). The procedures of blot analyses of flotillin-1 and thin-layer chromatography (TLC) of cholesterol were the same as described in our preceding publication (Nakamura et al. 2013). Semi-quantitative TLC analysis of cholesterol was performed according to the method described previously (Kotosai et al. 2013).

UV-A irradiation of cells $(800 \mu \mathrm{W}$ at $2 \mathrm{~h})$ was conducted after the incubation with $\alpha-\mathrm{T}(5 \mu \mathrm{M})$ or $\alpha-\mathrm{T} 3(0.5 \mu \mathrm{M})$ for $24 \mathrm{~h}$ and replacement with culture medium containing $1 \mu \mathrm{M}$ hematoporphyrin, and $\mathrm{ChOOHs}$ were measured as described previously (Nakamura et al. 2013).

Results are the means \pm S.D. $(n=3$ or $n=4)$. Statistical analyses were carried out using the Student's $t$-test. $\mathrm{P}<$ 0.05 was considered significant.

\section{Results and discussion}

Several reports have clarified that cellular uptake of $\alpha$ T3 is much more efficient than that of $\alpha-\mathrm{T}$ when mixed with cultured cells (Saito et al. 2010; Nishio et al. 2013). To adjust the contents of $\alpha-\mathrm{T}$ and $\alpha-\mathrm{T} 3$ in fibroblasts, $\alpha-\mathrm{T}$ and $\alpha$-T3 $(0.05-5 \mu \mathrm{M})$ were added to cells and then incubated for $24 \mathrm{~h}$. Treatment at $5 \mu \mathrm{M}$ and $0.5 \mu \mathrm{M}$ raised a similar level in cells for $\alpha-\mathrm{T}(0.70 \pm$ $0.03 \mathrm{nmol} / \mathrm{mg}$ protein) and $\alpha-\mathrm{T} 3(0.43 \pm 0.04 \mathrm{nmol} / \mathrm{mg}$ protein), respectively (Figure 1). Therefore, we adopted $5 \mu \mathrm{M}$ for $\alpha-\mathrm{T}$ and $0.5 \mu \mathrm{M}$ for $\alpha-\mathrm{T} 3$ for investigation of the distribution of $\alpha-\mathrm{T}$ and $\alpha-\mathrm{T} 3$ to the microdomains of cell membranes in fibroblasts.

In the partition experiment, microdomain regions were assumed to be fractions 3, 4 and 5, based on the results of dot-blot analysis of a marker protein of microdomains, flotillin-1 (Figure 2A). This figure also shows that flotillin-1 at the fractions 3,4 and 5 was decreased upon $\mathrm{M} \beta C D$ treatment. Cholesterol in the microdomain region (fraction 4 ) also decreased notably ( $55 \%$ of notreated fraction 4) after the treatment of $\mathrm{MBCD}$ (Figure $2 \mathrm{~B}$ ). Thus, it was evident that $M \beta C D$ treatment could remove cholesterol resulting in the perturbation of microdomain structures (Zidovetzki and Levitan 2007). However, this treatment did not affect the distribution of $\alpha$-T3 to each fraction (Figure 3). In contrast, $\alpha-\mathrm{T}$ content in the microdomain regions was lowered significantly (approx. 9\%) by $\mathrm{M} \beta C D$ treatment. Total amount of $\alpha-\mathrm{T}$ in the cells after M $\beta C D$ treatment was significantly decreased from $756.3 \pm$ $27.5 \mathrm{pmol} / \mathrm{mg}$ protein to $635.3 \pm 42.9 \mathrm{pmol} / \mathrm{mg}$ protein, although that of $\alpha-\mathrm{T} 3$ showed no significant decrease from $461.3 \pm 13.8 \mathrm{pmol} / \mathrm{mg}$ protein to $402.9 \pm 44.8 \mathrm{pmol} / \mathrm{mg}$ protein. It is assumed that some $\alpha-T$ was released in the cultured medium by the disruption of microdomains. These results suggested that $\alpha-\mathrm{T}$ (not $\alpha-\mathrm{T} 3$ ) was partially located or bound to cholesterol-rich microdomains. In addition to cholesterol, glycosphingolipids are also highly concentrated in the microdomains. Here, we focused on cholesterol because our preceding study suggest activation of MMPs in the UVA-exposed skin is triggered by preferential formation of ChOOHs in the microdomains (Minami et al. 2009).

It has been hypothesized that $\alpha-\mathrm{T}$ is not partitioned into microdomains (Atkinson et al. 2010). Whereas, Royer et al. implied that $\alpha-\mathrm{T}$ is loosely bound to lipid raft domains (Royer et al. 2009). Lemaire-Ewing et al. emphasized that $\alpha$-T shows a propensity to associate with lipid raft domains (Lemaire-Ewing et al. 2010). Yoshida et al. demonstrated that tocopherols and tocotrienols have similar mobility within membranes (Yoshida et al. 2003). Serbinova et al. implied that $\alpha$ T3 is more uniformly distributed in bilayer membranes and possesses higher recycling efficiency from chromanoxy radicals than $\alpha-T$ (Serbinova et al. 1991). However, there are no reports on the distribution of $\alpha-\mathrm{T} 3$ to the microdomains in cell membranes. Here, we found that $\alpha$-T (but not $\alpha-\mathrm{T} 3$ ) was partially localized or bound to cholesterol-rich microdomains, as indicated 


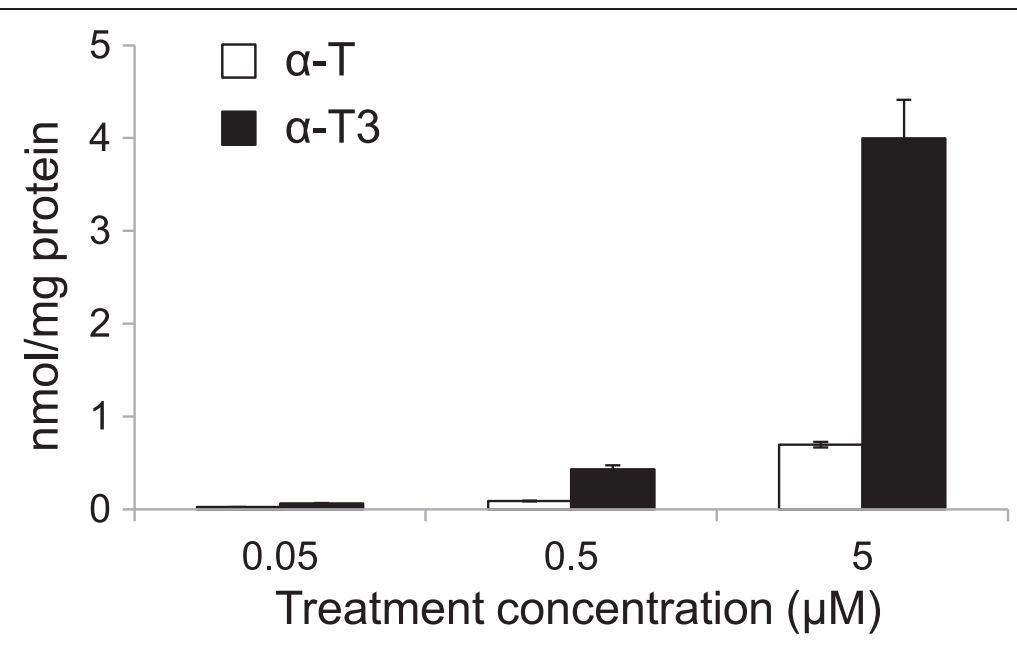

Figure 1 Cellular uptake of $\mathbf{a}-\mathrm{T}$ and $\mathbf{a}-\mathrm{T} 3$ at different concentrations. $\mathrm{a}-\mathrm{T}$ or $\mathrm{a}-\mathrm{T} 3$ at the concentration in the range between 0.05 and $5 \mu \mathrm{M}$ was incubated with fibroblasts for $24 \mathrm{~h}$. White bars, $\mathrm{a}-\mathrm{T}$; black bars, $\mathrm{a}-\mathrm{T} 3$. Values are the means \pm S.D. $(n=3)$.

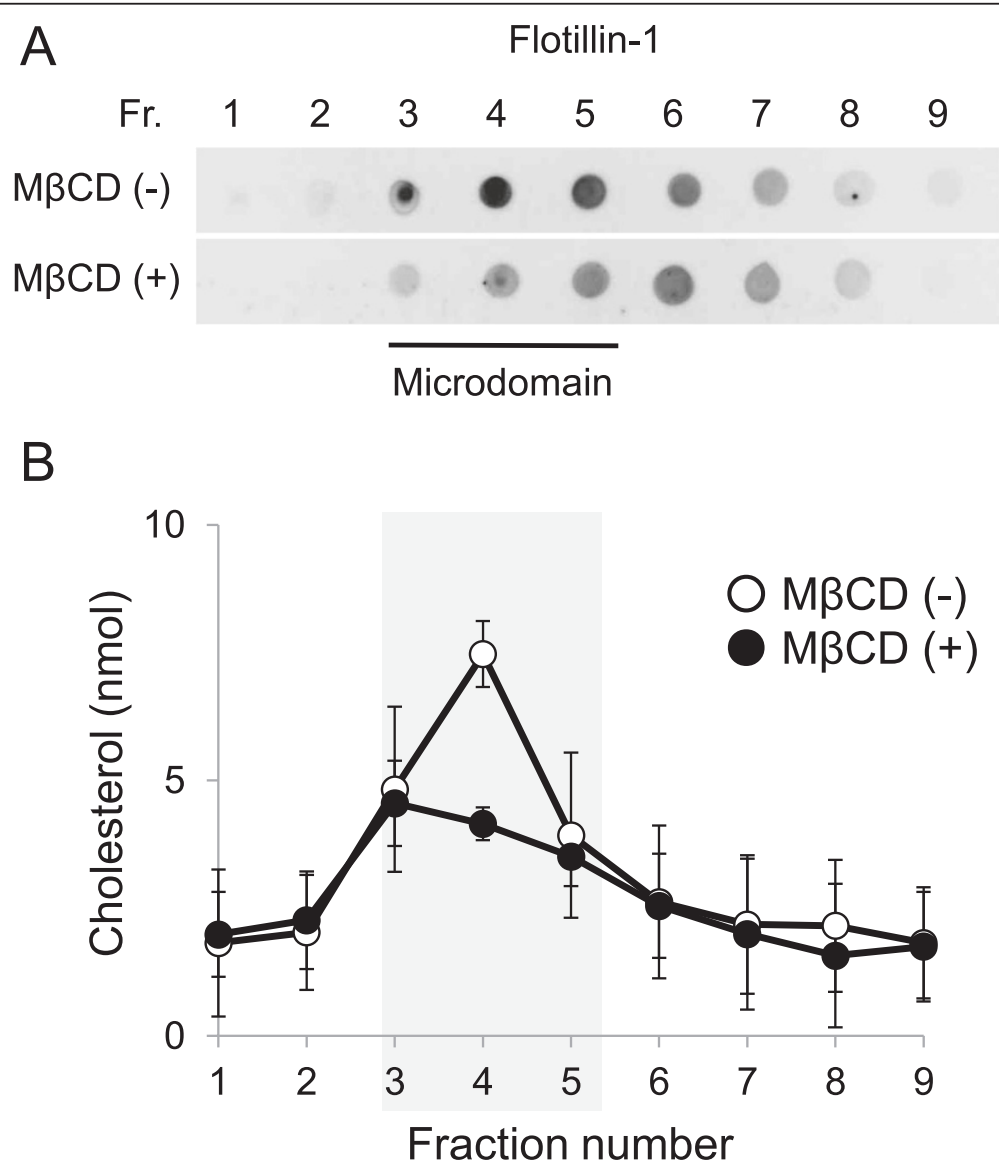

Figure 2 Effect of $M \beta C D$ on the distribution of flotillin-1 and cholesterol in microdomain fractions. After 30 min incubation of fibroblast with serum-free DMEM in the presence of $10 \mathrm{mM} \mathrm{M \beta CD}(M \beta C D(+))$ or in the absence of $M \beta C D(M \beta C D(-))$, cell lysates were subjected to ultracentrifugation $\left(268,000 \times \mathrm{g}\right.$ for $4 \mathrm{~h}$ at $\left.4^{\circ} \mathrm{C}\right)$ and split into nine fractions. (A) Dot blot analyses of flotillin-1. (B) Semi-quantitative TLC analyses of cholesterol. Open circles, no treatment; closed circles, treatment with M $B C D$. Values are the means \pm S.D. $(n=3)$. 

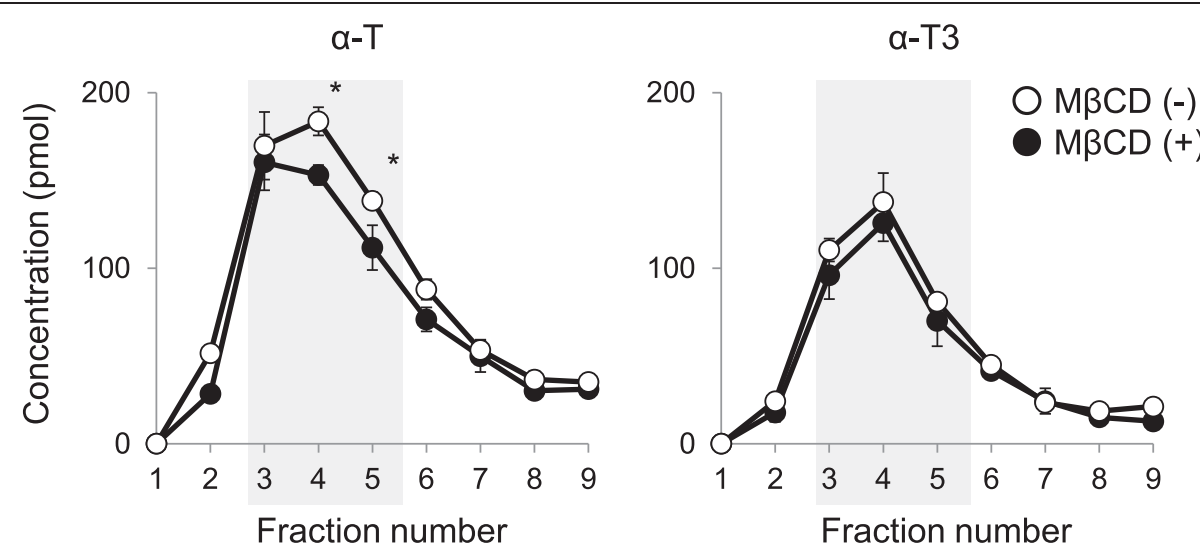

Figure 3 Changes in the distribution of $\mathbf{\alpha}-\mathbf{T}$ and $\mathbf{\alpha}-\mathrm{T} 3$ upon treatment with $\mathbf{M} \beta \mathbf{C D}$. $\mathbf{\alpha}-\mathrm{T}(5 \mu \mathrm{M})$ or $\mathbf{\alpha}-\mathrm{T} 3(0.5 \mu \mathrm{M})$ was incubated with fibroblasts for $24 \mathrm{~h}$ and replaced with serum-free DMEM in the presence of $10 \mathrm{mM} \mathrm{M \beta CD} \mathrm{(M \beta CD} \mathrm{(+))} \mathrm{or} \mathrm{in} \mathrm{the} \mathrm{absence} \mathrm{of} M \beta C D(M \beta C D(-))$. After incubation for $30 \mathrm{~min}$, cell lysates were subjected to ultracentrifugation and fractionated by the same method as that shown in Figure 2 . Open circles, no treatment; closed circles, treatment with $M \beta C D$. Values are the means \pm S.D. $(n=3)$. Asterisk indicates a significant difference between treatment group and no-treatment group $(P<0.05)$.

previously (Royer et al. 2009; Lemaire-Ewing et al. 2010). In contrast, $\alpha-\mathrm{T} 3$ is unlikely to be located selectively in cholesterol-rich microdomains or prefers to be located in this region. Furthermore, we investigated the inhibition of production of ChOOHs by $\alpha-\mathrm{T}(5 \mu \mathrm{M})$ or $\alpha$-T3 $(0.5 \mu \mathrm{M})$ in fibroblasts. Three $\mathrm{ChOOH}$ isomers, cholesterol $7 \alpha$-hydroperoxide $(\mathrm{Ch} 7 \alpha \mathrm{OOH})$, cholesterol
$5 \alpha$-hydroperoxide $(\mathrm{Ch} 5 \alpha \mathrm{OOH})$ and cholesterol $7 \beta-$ hydroperoxide $(\mathrm{Ch} 7 \mathrm{\beta OOH})$ ), were then determined by instrumental analyses. Each hydroxy derivative $(\mathrm{Ch} 7 \alpha \mathrm{OH}$, $\mathrm{Ch} 5 \alpha \mathrm{OH}$ and $\mathrm{Ch} 7 \beta \mathrm{OH}$ ) derived from its respective $\mathrm{ChOOH}$ isomer was increased significantly by exposure to UV-A light (Figure 4). However, UV-A-induced production of these ChOOHs was suppressed by treatment with

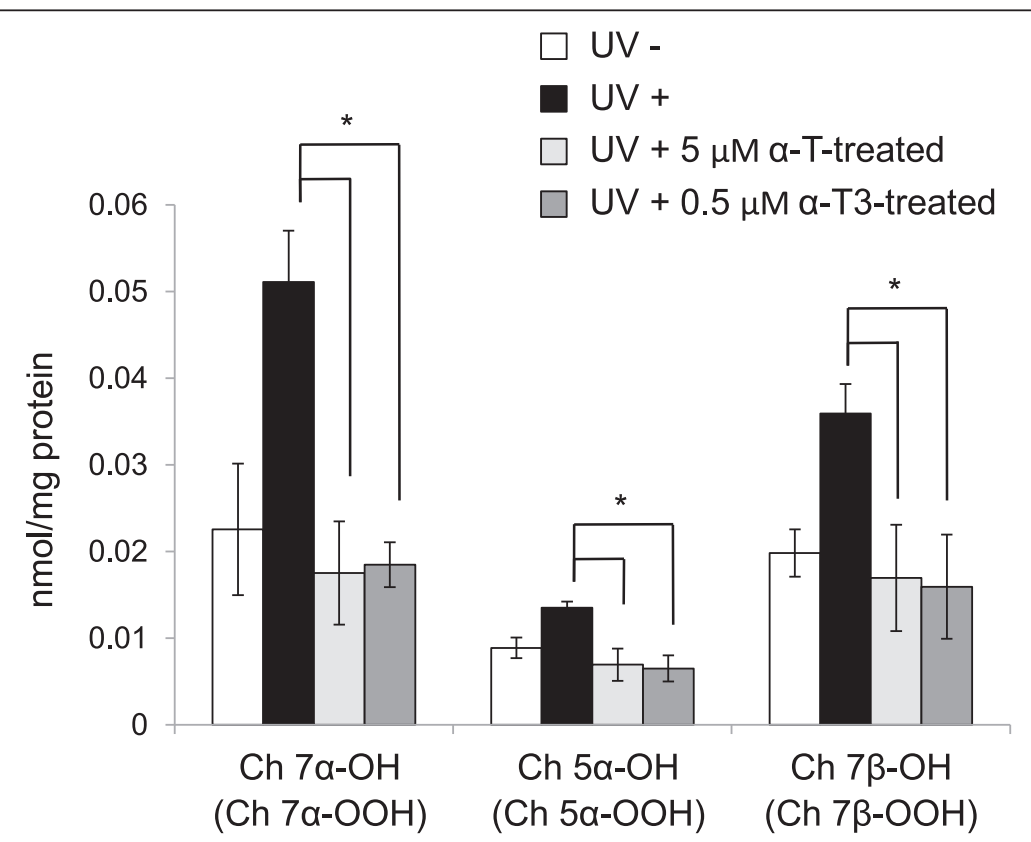

Figure 4 Inhibitory effect of $\mathbf{a}-\mathrm{T}$ and $\mathbf{\alpha}-\mathrm{T3}$ on the production of ChOOHs in UV-A-irradiated fibroblasts. Cells were irradiated with UV-A light $(800 \mu \mathrm{W})$ for $2 \mathrm{~h}$ in the presence of hematoporphyrin $(1 \mu \mathrm{M})$. After irradiation, lipids were extracted and subjected to TLC blotting and gas chromatography-mass spectrometry analyses. White bars, no irradiation; black bars, irradiation with UV-A; light-gray bars, irradiation with UV-A after treatment with a-T $(5 \mu M)$ for 24 h; dark-gray bars, irradiation with UV-A after treatment with a-T3 $(0.5 \mu M)$ for 24 h. Values are the means \pm S.D. $(n=4)$. Asterisks indicate significant difference between the non-treatment group with irradiation (black bars) and a-T/a-T3-treated group. 
$\alpha-T$ and $\alpha$-T3. The level of the suppression by $\alpha$-T3 was approximately the same as that by $\alpha-T$. Our previous report (Nakamura et al. 2013) indicates that isomeric $\mathrm{ChOOHs}$ are produced equally in both microdomains and non-microdomains. Thus, both of $\alpha-\mathrm{T}$ and $\alpha$-T3 seem to suppress the production of $\mathrm{ChOOHs}$ at similar degree, although their localization in the microdomains are not the same. The photodynamic actions of hematoporphyrin generate singlet molecular oxygen $\left({ }^{1} \mathrm{O}_{2}\right)$ to result in $\mathrm{Ch} 5 \alpha \mathrm{OOH}$ as a ${ }^{1} \mathrm{O}_{2}$-specific oxidation product, and $\mathrm{Ch} 7 \alpha \mathrm{OOH}$ and $\mathrm{Ch} 7 \beta \mathrm{OOH}$ can be formed via isomerization of $\mathrm{Ch} 5 \alpha \mathrm{OOH}$ (Girotti and Korytowski 2000; Niki 2005). Although cholesterol $6 \alpha$-hydroperoxide and cholesterol $6 \beta$-hydroperoxide are formed in the type-II reaction as minor prodcuts (Korytowski and Girotti 1999), we focused a major product, $\mathrm{Ch} 5 \alpha \mathrm{OOH}$, and its isomerization products. Tocopherols are known to possess efficient ${ }^{1} \mathrm{O}_{2}$-quenching activity in biomembranes (Fukuzawa et al. 1997). The ${ }^{1} \mathrm{O}_{2}$-quenching activities of $\alpha-\mathrm{T}$ and $\alpha-\mathrm{T} 3$ are, theoretically, dependent upon the structure of the chromanol group and independent of the side chains (Gruszka et al. 2008). Our result that $\alpha$ T3 exerted comparable inhibition to that of $\alpha-T$ implies that $\alpha-\mathrm{T} 3$ participates in the prevention of photoaging by effective antioxidation in the skin, even though the behavior of $\alpha-\mathrm{T} 3$ in the heterogeneous cell membranes is different from that of $\alpha-\mathrm{T}$.

In conclusion, it is not evident that $\alpha-\mathrm{T} 3$ is located in cholesterol-rich microdomains, although $\alpha-\mathrm{T}$ is (at least in part) located or bound to this region of heterogeneous cell membranes. Nevertheless, $\alpha-\mathrm{T} 3$ can suppress the production of $\mathrm{ChOOHs}$ from membranous cholesterol mediated by the photodynamic actions of hematoporphyrin to the same extent as that seen with $\alpha-T$.

\section{Abbreviations \\ a-T: a-tocopherol; a-T3: a-tocotrienol; $\mathrm{ChOOH}$ : Cholesterol hydroperoxide; UV: Ultraviolet; MMPs: Matrix metalloproteinases; DMEM: Dulbecco's modified Eagle's medium; Ch5aOOH: Cholesterol 5a-hydroperoxide; Ch7aOOH: Cholesterol 7a-hydroperoxide; $\mathrm{Ch7} \beta \mathrm{OOH}$ : Cholesterol 7 $\beta$-hydroperoxide; $M \beta C D$ : Methyl- $\beta$-cyclodextrin; ${ }^{1} \mathrm{O}_{2}$ : Singlet molecular oxygen.}

\section{Competing interests}

The authors declare that they have no competing interests.

\section{Authors' contributions}

TN and JT made contributions to the conception and design. TN and AN performed the experiments. All authors read and approved the final manuscript.

\section{Author details}

'Department of Food Science, Institute of Health Bioscience, Tokushima University Graduate School, 3-18-15 Kuramoto-cho, Tokushima 770-8503, Japan. ${ }^{2}$ Present address: School of Food and Nutrition Sciences, University of Shizuoka, Shizuoka, Japan.

Received: 17 August 2014 Accepted: 18 September 2014 Published: 23 September 2014

\section{References}

Atkinson J, Harroun T, Wassall SR, Stillwell W, Katsaras J (2010) The location and behavior of alpha-tocopherol in membranes. Mol Nutr Food Res 54:641-651

Bando N, Yamanishi R, Terao J (2003) Inhibition of immunoglobulin E production in allergic model mice by supplementation with vitamin $\mathrm{E}$ and beta-carotene. Biosci Biotechnol Biochem 67:2176-2182

Fukuzawa K, Matsuura K, Tokumura A, Suzuki A, Terao J (1997) Kinetics and dynamics of singlet oxygen scavenging by alpha-tocopherol in phospholipid model membranes. Free Radic Biol Med 22:923-930

Girotti AW, Korytowski W (2000) Cholesterol as a singlet oxygen detector in biological systems. Methods Enzymol 319:85-100

Gruszka J, Pawlak A, Kruk J (2008) Tocochromanols, plastoquinol, and other biological prenyllipids as singlet oxygen quenchers-determination of singlet oxygen quenching rate constants and oxidation products. Free Radic Biol Med 45:920-928

Hosomi A, Arita M, Sato Y, Kiyose C, Ueda T, Igarashi O, Arai H, Inoue K (1997) Affinity for alpha-tocopherol transfer protein as a determinant of the biological activities of vitamin E analogs. FEBS Lett 409:105-108

Ikeda S, Niwa T, Yamashita K (2000) Selective uptake of dietary tocotrienols into rat skin. J Nutr Sci Vitaminol (Tokyo) 46:129-139

Ikeda S, Tohyama T, Yoshimura H, Hamamura K, Abe K, Yamashita K (2003) Dietary alpha-tocopherol decreases alpha-tocotrienol but not gamma-tocotrienol concentration in rats. J Nutr 133:428-434

Korytowski W, Girotti AW (1999) Singlet oxygen adducts of cholesterol: photogeneration and reductive turnover in membrane systems. Photochem Photobiol 70:484-489

Kotosai M, Shimada S, Kanda M, Matsuda N, Sekido K, Shmizu Y, Tokumura A, Nakamura T, Murota K, Kawai Y, Terao J (2013) Plasma HDL reduces nonesterified fatty acid hydroeproxides originating from oxidized LDL: a mechanism for its antioxidant ability. Lipids 48:569-578

Lemaire-Ewing S, Desrumaux C, Neel D, Lagrost L (2010) Vitamin E transport, membrane incorporation and cell metabolism: is alpha-tocopherol in lipid rafts an oar in the lifeboat? Mol Nutr Food Res 54:631-640

Minami Y, Kawabata K, Kubo Y, Arase S, Hirasaka K, Nikawa T, Bando N, Kawai Y, Terao J (2009) Peroxidized cholesterol-induced matrix metalloproteinase-9 activation and its suppression by dietary beta-carotene in photoaging of hairless mouse skin. J Nutr Biochem 20:389-398

Nakamura T, Noma A, Shimada S, Ishii N, Bando N, Kawai Y, Terao J (2013) Non-selective distribution of isomeric cholesterol hydroperoxides to microdomains in cell membranes and activation of matrix metalloproteinase activity in a model of dermal cells. Chem Phys Lipids 174:17-23

Niki E (2005) Lipid peroxidation: Mechanisms, inhibition, and biological effects. Biochem Biophys Res Commun 338:668-676

Niki E, Yamamoto Y, Takahashi M, Komuro E, Miyama Y (1989) Inhibition of oxidation of biomembranes by tocopherol. Ann N Y Acad Sci 570:23-31

Nishio K, Horie M, Akazawa Y, Shichiri M, Iwahashi H, Hagihara Y, Yoshida Y, Niki E (2013) Attenuation of lipopolysaccharide (LPS)-induced cytotoxicity by tocopherols and tocotrienols. Redox Biol 1:97-103

Royer MC, Lemaire-Ewing S, Desrumaux C, Monier S, Pais de Barros JP, Athias A, Néel D, Lagrost L (2009) 7-ketocholesterol incorporation into sphingolipid/ cholesterol-enriched (lipid raft) domains is impaired by vitamin E: a specific role for alpha-tocopherol with consequences on cell death. J Biol Chem 284:15826-15834

Saito Y, Nishio K, Ogawa-Akazawa Y, Yamanaka K, Miyama A, Yoshida Y, Noguchi N, Niki E (2010) Cytoprotective effects of vitamin E homologues against glutamate-induced cell death in immature primary cortical neuron cultures: Tocopherols and tocotrienols exert similar effects by antioxidant function. Free Radic Biol Med 49:1542-1549

Serbinova E, Kagan V, Han D, Packer L (1991) Free radical recycling and intramembrane mobility in the antioxidant properties of alpha-tocopherol and alpha-tocotrienol. Free Radic Biol Med 10:263-275

Simons K, Ikonen E (1997) Functional rafts in cell membranes. Nature 387:569-572

Suzuki YJ, Tsuchiya M, Wassall SR, Choo YM, Govil G, Kagan VE, Packer L (1993) Structural and dynamic membrane properties of alpha-tocopherol and alpha-tocotrienol: implication to the molecular mechanism of their antioxidant potency. Biochemistry 32:10692-10699

Yamashita K, Ikeda S, lizuka Y, Ikeda I (2002) Effect of sesaminol on plasma and tissue alpha-tocopherol and alpha-tocotrienol concentrations in rats fed a vitamin E concentrate rich in tocotrienols. Lipids 37:351-358 
Yoshida Y, Niki E, Noguchi N (2003) Comparative study on the action of tocopherols and tocotrienols as antioxidant: chemical and physical effects. Chem Phys Lipids 123:63-75

Zidovetzki R, Levitan I (2007) Use of cyclodextrins to manipulate plasma membrane cholesterol content: evidence, misconceptions and control strategies. Biochim Biophys Acta 1768:1311-1324

doi:10.1186/2193-1801-3-550

Cite this article as: Nakamura et al:: Location of a-tocopherol and a-tocotrienol to heterogeneous cell membranes and inhibition of production of peroxidized cholesterol in mouse fibroblasts. SpringerPlus 2014 3:550

Submit your manuscript to a SpringerOpen ${ }^{\circ}$ journal and benefit from:

- Convenient online submission

- Rigorous peer review

- Immediate publication on acceptance

- Open access: articles freely available online

- High visibility within the field

- Retaining the copyright to your article

Submit your next manuscript at $>$ springeropen.com 